\title{
Charles d'Orléans, duas canções e uma trajetória
}

Ivone C. Benedetti

A situação social de Charles d'Orléans sem dúvida contribuiu muito para o conhecimento que hoje se tem de sua obra. Em vida, esse príncipe (neto, sobrinho e pai de reis) conseguiu montar um manuscrito autógrafo, a partir do qual Pierre Champion pôde estabelecer a compilação mais respeitada hoje em dia, cujos poemas, apresentados em seqüência cronológica aproximada, nos possibilitam estudar a evolução temática dessa poética. A expressão "evolução temática" merece um comentário preliminar. Temas e motivos praticamente não mudam do começo ao fim dessa trajetória poética; o que varia de fato é o tratamento a eles dispensado.

Champion propôs a seqüência cronológica da poética do príncipe em 1927, numa obra que foi reeditada em 1971, em dois volumes. $\bigcirc$ primeiro é dedicado a baladas, canções, complaintes e caroles, enquanto o segundo contém os rondéis. Pelo que se depreende dessa compilação, embora o grosso da composição da juventude de Charles d'Orléans tenha sido constituído por baladas, o poeta também as compôs na maturidade. $\bigcirc$ primeiro volume de Champion, portanto, deve ser manuseado com cuidado na tentativa de distinguir, pelas características dos 
poemas, aqueles que pertencem à maturidade e os que pertencem à juventude. No fim do volume encontram-se as baladas que, de modo geral, podem ser arroladas entre os poemas da idade madura. Sabe-se que só nesta última fase Charles d'Orléans se dedicou sistematicamente à composição de rondéis. A composição de canções, segundo Champion, não tem elementos cronológicos para estabelecer com clareza as datas de produção.

A análise temática pode fornecer chaves preciosas para $\circ$ estudo da evolução dessa poética. $\bigcirc$ que se mostra, logo à primeira vista, é uma fidelidade espantosa à temática do amor cortês, que vicejou a partir do Roman de la Rose. Ou seja, a obra toda é permeada por uma mitologia montada em torno de umas poucas dezenas de personificações, que "interagem" como personagens de uma comédia que o autor foi construindo ao longo da vida. Um estudo mais atento também mostra que, se no início tais personificações/personagens se vestem da púrpura das grandes personalidades, no fim já não ostentam nenhum manto suntuoso: sua roupagem, se não chega a ser burguesa, é de uma nobreza menos solene, mais risonha, mais brincalhona. Ou elas simplesmente desaparecem para dar lugar a uma meditação mais jocosa, irônica, desenganada, quando não ressentida.

É esse tratamento final que observamos nas canções abaixo. As personificações desapareceram, e o que ficou foi o tratamento jocoso de uma temática que antes chegara a ganhar nuances mitológicas: a corte amorosa.

Mas essa afirmação, de que tais canções se enquadram num tipo de tratamento característico da maturidade do poeta, põenos em rota de colisão com as afirmações de Champion. Este, ao tratar das chansons (1971, p. XXV), nos diz que "Faltam elementos cronológicos na maioria das vezes. Entre todas as peças líricas, estas, destinadas a ser cantadas (o duque de Orléans era muito dado à música) conformam-se à tradição cortês e discreta. Toda- 
via, cabe observar que o maior número de canções data da estada de Charles d'Orléans na Inglaterra, que as primeiras são talvez anteriores a 1415. No manuscrito, elas se apresentam como pertencentes à formação mais antiga da coleção" [trad. minha]. Champion, no entanto, é em parte contraditado por Poirion (1978, p. 294), que nos diz, ao comentar as viagens feitas pelo poeta (após a volta do exílio) a terras de Itália e França: "Essas viagens tiveram pelo menos o mérito de fazê-lo conhecer numerosos amantes de poesia: suas relações se enriquecem, e é nessa época que se desenvolvem as trocas de rondéis que transformarão seu manuscrito num álbum coletivo. Esses novos poemas, inscritos depois do fundo inicial, já não são realmente canções destinadas à música. Por isso, depois de certo tempo de hesitação (ms. O, p. 347-348), os rubricadores substituirão a menção "chanson" por "rondeau". Apesar dessa diferença, na qual Champion cometeu o erro de basear a classificação dos poemas, convém seguir a ordem do manuscrito, confirmada por uma numeração do duque, para entender esse diário poético, que encontramos na parte de baixo das páginas, mas também, às vezes, na parte superior, que ficou disponível com o abandono do projeto musical." E em nota: "Encontramos sucessivamente: Ro. 1 a 18, Ch. 69-81, Ro. 19-23, Ch. 82-87, depois os rondeaux 24 e ss." [trad. minha]. Assim, se Champion afirma (no que não é desmentido por Poirion) que os rondéis começaram a ser compostos em 1443 (depois do exílio), e se Poirion, seguindo critério diferente do de Champion, inclui as canções 69-81 entre os rondéis, confirma-se nossa impressão, diante do estilo do poema, de que se trata realmente de uma obra da maturidade, ainda que Charles d'Orléans tenha declarado o esquecimento desse tipo de composição (ao lado das baladas e das complaintes):

Ballades, chansons et complaintes

Sont par moi mises en oubli. 
BENEDETTI, Ivone C. Charles d'Orléans, duas canções e uma trajetória

Ora, se sabemos que ele de fato não esqueceu as baladas, que as compôs na maturidade, por que não teria dispensado tratamento semelhante às canções (que tantas semelhanças formais, aliás, tinham com os rondéis)?

Na primeira canção aqui apresentada, encontra-se um motivo muito freqüente na maturidade: o poeta é espectador do jogo amoroso; descreve-o, não o joga. As peças desse jogo perderam valor emocional, lírico (nunca se pode falar em dramaticidade com referência a Charles d'Orléans), mas a partida ganha em brejeirice, em nonchaloir, em descuidar, em descaso. Os valores mudam, e o eu poético já consegue rir daquilo que antes era objeto de grande seriedade. As formas poéticas tendem a reduzir-se, alguns poemas chegam a ser minimalistas. Os pensamentos são expressos de maneira mais incisiva: o vocabulário perde em prolixidade, em redundância, e ganha em concretude de sentidos.

A primeira canção é a de número LXXIII e está na página 247 da coleção de Pierre Champion (CHAMPION, 1971). O motivo do poema é a corte amorosa, ou seja, motivo tradicionalmente bastante explorado pelo poeta. Mas, ao contrário do que se vê nos poemas da juventude, em que freqüentemente um amante presta homenagem ao rei do Amor - príncipe que vive rodeado por uma corte de que fazem parte Beleza, Esperança, Amenidade, Perigo etc. -, o clima já não é de diáfana mitologia pagano-cristã: as personagens já não são personificações, são entes quase palpáveis; já se fazem presentes certas minúcias da realidade concreta (por exemplo, fogo extraído do pavimento pelas patas dos cavalos), numa exploração inusitada de imagens visuais. Fato interessante é que já se observa com mais freqüência uma construção metafórica em que entram em contato isotopias diferentes (em lugar da temática simplesmente recorrente de antes, que configuraria uma isotopia temática [GREIMAS, 1979; DUBOIS et al., 1977]): os cavaleiros são esporados tanto quanto os cavalos, num entrelaçamento que mescla as isotopias "humano" e "animal", 
remetendo, por associação, à idéia de força do aguilhão sexual, imagem inconcebível nos poemas da juventude, mesmo na forma velada com que é apresentada aqui. Não há lirismo, há gracejo; não há participação, há distanciamento irônico.

A tradução não poderia perder de vista esses elementos, além dos formais. Formalmente, o poema é construído segundo uma "forma fixa" que reúne estrofes portadoras de refrões que no caso se distribuem segundo o esquema $\mid\{A B b a\} ;\|\{a b A B\} ;\| I\{a b b a A\}$, em que os números romanos representam as estrofes e as letras entre chaves representam as rimas (as maiúsculas representam os versos de refrão). Conforme se vê, trabalha-se apenas com duas rimas: é fácil imaginar que a observância de um esquema rímico assim restrito dificulta sobremaneira a tradução. No entanto, não nos parece lícito traduzir sem essa observância um poema pertencente a uma escola estética que tinha como uma de suas marcas, de suas características típicas, exatamente tais formas fixas.

Destacaríamos como outros recursos poéticos de observação obrigatória: a seqüência de palavras semanticamente próximas (a expressão "jeunes amoureux nouveaux" seguida de "en la nouvelle saison") que constitui uma recorrência cujo objetivo é enfatizar e associar as idéias de juventude, novidade e "noviciado" (no amor). Idéia que se desdobra na segunda estrofe com a imagem visual (dos cavalos arrancando fogo do pavimento) a que aludimos: só do atrito entre a agudeza e a lisura do ferro e do pavimento é que saem chispas, de resto como também só do carvão novo e seco é que se extrai fogo. Destaque-se também que os versos em que tais palavras (jeunes, nouveaux, nouvelle) se encontram são exatamente os versos de refrão.

Além disso, não se pode deixar de dar o devido peso à aliteração entre as nasais $n-m-n$ em alternância com as fricativas $j-v$ tendo de permeio a vibrante $r$, bem como à assonância entre os grupos vocálicos "fortes" que acompanham cada uma dessas consoantes: eu-ou-eu-ou-eau (a única exceção é o-e mudo final de 
jeunes), o que empresta ao verso uma cadência bastante regular (lembramos, mais uma vez que esse é o verso do refrão, e que essa é uma composição tradicionalmente feita para ser cantada). Tentei recuperar essa seqüência com Jovens novéis namorados. $\bigcirc$ adjetivo "novéis", de sabor antiquado e prosodicamente bem próximo de nouveaux, tem a vantagem de entrelaçar em si as idéias de novo e novato, ao mesmo tempo que ajuda a reproduzir a aliteração presente no poema francês).

Finalmente, cabe notar que os poemas da época tinham forte teor retórico discursivo. Explico: as estrofes iniciais sempre dispunham uma seqüência de idéias (segundo esquemas mais ou menos rígidos de exposição) que, na última, redundavam em maior complexidade sintática (maior freqüência de orações subordinadas, por exemplo) e ideativa. Isso era praxe. Neste tipo de poema, da maturidade, o poeta reserva os versos da última estrofe não só para a (re)criação desses efeitos mas também para neles introduzir a sua pitada de humor, de ironia: é neles que o eu poético se dá ao luxo de brincar com as imagens que lhe calçaram a trajetória da (sisuda) juventude.

Característica pouco usual, ostentada por essa primeira canção, é a contagem heptassilábica dos versos. De fato, Poirion nos dá os números da poética de Charles d'Orléans: nas baladas, nenhuma ocorrência de versos heptassílabos (POIRION, 1978, p. 370); nos rondéis, duas ocorrências (1978, p. 352); nas canções, salvo melhor juízo, essa é a única da coleção. $\bigcirc$ fato é interessante porque, em contrapartida, é enorme a freqüência de octossílabos, tanto em Charles d'Orléans quanto em outros poetas de sua época. De tal maneira que se pode dizer que o octossílabo está para a poesia francesa da época assim como o heptassílabo está para a portuguesa (Cf. SPINA, 1971, p. 24). A tradução dessa canção em heptassílabos rende assim um ritmo bastante familiar aos ouvidos lusófonos, ao contrário do que ocorre em parte com o verso octossílabo (no qual é composta a outra canção deste trabalho). 
A tradução proposta é a seguinte:

\section{CANÇÃO LXXIII}

Jovens, novéis namorados,

Chegada a nova estação,

Pelas ruas, sem razão,

Vão saltando em cavalgada.

E fogo, do chão calçado,

Arrancam, qual do carvão.

Jovens, novéis namorados,

Chegada a nova estação.

Não sei se é bem empregado

Tanto trabalho, se não.

Mas qual seus cavalos vão

Os donos esporeados.

Jovens, novéis namorados.

\section{CHANSON LXXIII}

Jeunes amoureux nouveaux,

En la nouvelle saison,

Par les rues, sans raison

Chevauchent faisant les sauts. 
BENEDETTI, Ivone C. Charles d'Orléans, duas canções e uma trajetória

Et font saillir des carreaux

Le feu, comme de charbon:

Jeunes amoureux nouveaux

En la nouvelle saison.

Je ne sais si leurs travaux

Ils emploient bien ou non;

Mais piqués de l'éperon

Sont autant que leurs chevaux,

Jeunes amoureux nouveaux.

A canção abaixo é a de número LXXIV da coleção de Champion, ou seja, a canção seguinte à que acabamos de traduzir.

\section{CANÇÃO LXXIV}

Cuida das setas da janela,

Amante que por ruas vais,

Porque são elas mais mortais

Que setas de arco, que quadrelos.

Não olhes esta parte, aquela,

Baixar os olhos convém mais.

Cuida das setas da janela,

Amante que por ruas vais.

Se médico por ti não zela,

E se ferido acaso cais, 
Recomenda a alma a Deus pai,

A morte é certa: ao padre apela.

Cuida das setas da janela.

\section{CHANSON LXXIV}

Gardez le trait de la fenestre,

Amans, qui par ruez passez,

Car plus tot en serez blessez

Que de trait d'arc ou d'alabestre

N'alez a destre ne a senestre

Regardant, mais le yeulx bessez;

Gardez le trait de la fenestre,

Amans, qui par ruez passez,

Se n'avez medecin, bon maistre,

Si tost que vous serez navrez

A Dieu soyez recommendez;

Mort vous tiens, demandez le prestre:

Gardez le trait de la fenestre.

Antes de mais nada, vale tecer algumas considerações formais. A estrutura formal dessas canções é idêntica à dos rondéis. Nelas se observa o uso do rentrement, que é a retomada do primeiro verso como refrão, de tal modo que ele encerra o poema como se fechasse um círculo. Essa semelhança, segundo os estudiosos, ensejou certa hesitação na nomenclatura dos manuscritos de poemas de Charles d'Orléans (POIRION, 1965/1978, p. 355), ou seja, o mesmo poema aparece ora como chanson, ora como 
rondeau. Não havendo notação musical nesses manuscritos, supõe-se que a rubrica chanson indicasse uma composição destinada ao canto. Na composição cantada, o refrão podia não ser retomado por inteiro: "As interpretações musicais encontradas nos cancioneiros do século XV revelam que o refrão podia ser cortado em vários lugares, pois pausas, cadências, vocalises ou poslúdios instrumentais encarregavam-se de retomar o tom" (POIRION, $1965 / 1978$, p. 355). Por isso, nas composições destinadas ao canto nem sempre havia, no rentrement, concatenação precisa de sentido com os outros versos.

Desse modo, o elemento inicial tem grande peso. É nele que se lança a idéia principal, é com ele que se termina o poema. Segundo Poirion (1965/1978: 356), "Temos aí um momento de equilíbrio entre a estética medieval, que põe à frente do poema toda a sua força e seu atrativo, e a estética do Renascimento, que cultivará a ponta final, o remate habilmente preparado." Parece óbvia nessas duas canções a preparação do "remate" como fecho capaz de concentrar a atenção do leitor/ouvinte e propiciarIhe a fruição pela captação de uma síntese inteligente daquilo que foi dito antes, pela chegada de um elemento inesperado, criado pela inventividade poética. Fazendo-se então eco a Galderisi (1993), pode-se afirmar que também nesse aspecto Charles d'Orléans estabelece uma ponte entre Idade Média e Renascimento (Galderisi atém-se apenas ao aspecto lexical). Nas duas canções aqui estudadas, os remates são de fato um remoque. Na primeira, equiparação entre montador e montaria; na segunda, o amante "flechado" é convidado a apelar ao médico e ao padre. Neste caso, o desfecho não é o padecimento amoroso em sua forma tradicional, mas sim um padecimento físico com feições banais. A mudança de plano - do metafórico (seta $=$ paixão amorosa) para o concreto (seta = arma mortal) - ocorre de um modo jocoso (se não houver médico, a morte é certa, procure o padre) que suscita a lembrança da morte cotidiana e prosaica. Esse desnível é o elemento ines- 
perado, capaz de despertar o interesse e conduzir a um desfecho diferente do que se esperaria da abertura do poema.

Finalmente, vale comentar um dado evidente: a afinidade temática entre as duas canções. Em ambas a "personagem" é a mesma: o amante; o cenário é o mesmo: a rua. É como se a canção LXXIV continuasse a LXXIII. $O$ amante, que na primeira cavalga afoito, é alertado na segunda a guardar-se de ser atingido pelas setas que voam das janelas. Como reminiscência da velha temática, os olhos são a porta de entrada do padecimento amoroso: as setas são lançadas, mas o amante que se mantém de olhos baixos não é atingido. Para quem leia esse poema sem conhecimento de toda a temática de Charles d'Orléans, o conseIho a manter os olhos baixos pode parecer sem nexo ou, pelo menos, perder grande parte do poder alusivo. Interessante, nesse sentido, é que Charles d'Orléans se contenta com aludir àquilo que antes afirmava às escâncaras: pelos olhos entra a paixão amorosa que atinge o coração; seu veículo, a beleza. A mitologia não está presente. Restam seus ecos.

\section{Bibliografia}

CHAMPION P., Charles d'Orléans, poésies, vol. I, Paris: Librairie Honoré Champion, 1971.

CHAMPION P., Charles d'Orléans, poésies, vol. I, Paris: Librairie Honoré Champion, 1966.

CIGADA, SL'Opera poetica di Charles d'Orléans, Milão: Società Editrice Vita e Pensiero, 1960.

GALDERISI, C. Le lexique de Charles d'Orléans dans les rondeaux, Genebra: Droz, 1993.

POIRION, D., (1965/1978) Le poète et le prince, l'évolution du lyrisme courtois de Guillaume de Machaut à Charles d'Orléans, Paris: Presses Universitaires de France, 1965. 
BENEDETTI, Ivone C. Charles d'Orléans, duas canções e uma trajetória

POIRION, D., Le lexique de Charles d'Orléans dans les ballades, Genebra: Droz, 1967.

SPINA, S., A lírica trovadoresca, São Paulo: EDUSC, 1996.

SPINA, S., Manual de versificação românica medieval, Rio de Janeiro: Ed. Gernasa, 1971. 